\title{
Aplicação de métodos geoelétricos para monitoramento da barragem de concreto da UHE Gov. José Richa
}

\author{
Application of geoelectrical methods for monitoring the concrete dam of the HPP Gov. José Richa \\ ROBERTO RAFAEL ZORZI* , AUGUSTINHO RIGOTI ** \\ * Inst. tec. Desenvolvimento - Lactec. zorzir@hotmail.com \\ ** Universidade Federal do Paraná
}

\begin{abstract}
Resumo
A utilização dos ensaios geofísicos no maciço da barragem da Usina Hidrelétrica Governador José Richa (Salto Caxias) teve como objetivo principal desenvolver metodologia complementar ao sistema de monitoramento hoje existente. Mais especificamente, o método SP ("self potential") foi usado com o objetivo de mapear os caminhos preferenciais da água, enquanto que os ensaios de resistividade tiveram um papel complementar, fornecendo informação sobre o grau de saturação (conteúdo em água) no corpo da barragem. $\mathrm{O}$ arranjo gradiente, pela maior praticidade que apresenta, foi o escolhido como arranjo eletródico mais adequado para mapeamento de variações laterais de resistividade em tal meio de alta resistência de contato concreto-eletrodos.
\end{abstract}

Palavras-chave: Chave: Barrragens, monitoramento, métodos geoelétricos

\begin{abstract}
The application of Geophysics to monitor the concrete body of the Salto Caxias dam had the main objective of developing a methodology complementary to the existing monitoring program. More specifically, the SP (Self Potential) method was used to map the preferential water pathways, while resistivity had a complementary role, providing information on the saturation degree (water content) in the dam body. The gradient was chosen as the electrode array best suited for mapping resistivity lateral variation in such a high concrete-electrode contact resistance medium.
\end{abstract}

Keywords: Dams, monitoring, geoelectric methods

\section{Introdução}

Acidentes de rompimento de barragens podem ser originados instantaneamente por força de eventos tectônicos, mas com maior probabilidade pode-se esperar que o processo de rompimento seja gradual, em conseqüência de descontinuidades que se criam no corpo da barragem ou na terminação de suas ombreiras. A percolação persistente pela água através das descontinuidades causa alteração, lixiviação, agravando o problema e deteriorando a resistência mecânica até o rompimento. A percolação pela água é denunciada por surgências a jusante, mas o caminho preferencial do fluxo é desconhecido.

Alguns métodos diretos de investigação, como furos de sondagem, são utilizados para inspecionar caminhos suspeitos, mas trata-se de investigações volumetricamente pouco representativas. Os métodos elétricos e sísmicos são muito utilizados nas fases de viabilidade e construção, porém pouco tem sido feito na fase de inspeção na engenharia de barragem (Oliveira, 1998). Entende-se que eles têm um papel importante a cumprir, também no período de monitoramento (Corwin, 1989), com o intuito de aumentar a vida útil do investimento.

Enquanto muitos estudos com SP e resistividade em barragens de terra são encontrados na literatura (Ellert \& Sanches, 1982, Gallas, 2000, lyomasa et al, 2005) nenhum caso foi encontrado para barragens onde métodos geofísicos são aplicados diretamente no concreto. Entendese por isto, que o presente estudo tem caráter original neste sentido. Com o sucesso na determinação da distribuição da resistividade no corpo da barragem revelando as zonas condutoras (zonas fraturas com percolação de água/fluídos), o presente estudo já demonstrou ter alcançado um excelente resultado

\section{Objetivos}

Este trabalho tem como objetivo principal a aplicação de métodos geoelétricos para avaliar as zonas saturadas e 
fluxo de água no interior da barragem de concreto da Usina Hidrelétrica Governador José Richa (Salto Caxias) no município de Capitão Leônidas Marques / PR. e com isto determinar metodologia(s) capaz(es) de detectar descontinuidades (fraturas ou fissuras) com percolação de água no maciço de concreto a fim de auxiliar no monitoramento das condições de integridade e vida útil da estrutura de concreto.

\section{Localização da área}

A usina Governador José Richa (Salto Caxias), em operação desde o mês de outubro de 1998, está localizada no rio Iguaçu a cerca de $204 \mathrm{~km}$ de sua foz, no município de Capitão Leônidas Marques distante aproximadamente 600 $\mathrm{km}$ de Curitiba. Possui uma barragem do tipo gravidade em concreto compactado com rolo (CCR), com face (montante) em concreto convencional, sendo uma das maiores estruturas do gênero no Brasil, com $1.083 \mathrm{~m}$ de comprimento na crista e altura máxima de $67 \mathrm{~m}$ em relação ao leito do rio. Possui um vertedouro, com núcleo de CCR revestido de concreto convencional, incorporado à barragem, com uma capacidade da ordem de $50.000 \mathrm{~m}^{3} / \mathrm{s}$. Os volumes de concreto envolvidos na construção foram de $945.600 \mathrm{~m}^{3}$ de CCR na barragem e de $546.000 \mathrm{~m}^{3}$ de concreto convencional (CCV) em todo o empreendimento.

Nos dois primeiros anos, após o enchimento do reservatório, foram constatadas 6 (seis) fissuras na estrutura (Figura 1), sendo as principais localizadas nos blocos B5, B8 e B11 (Soares, 2005).

Estas fissuras são regiões na barragem com razoáveis infiltrações, sendo nítida sua visualização tanto no interior da galeria quanto nos degraus de jusante. O efeito destas fissuras na estrutura concretada vem sendo monitorado e avaliado constantemente. Segundo Soares (op cit), acredita-se que a ocorrência das fissuras dos blocos B5, B8 e B11, é de origem térmica, resultante do resfriamento da massa de concreto da barragem.

$A$ área de estudo escolhida foi a região entre os blocos B10, B11 e B12, privilegiando desta forma, a zona de fissura do bloco B11, que visualmente, apresentava uma das piores condições.

\section{Geologia da área}

No contexto geológico, a área de estudo está localizada no terceiro planalto paranaense, numa região enquadrada no denominado Altiplano Basáltico Paranaense e é predominantemente recoberta por uma sucessão de derrames basálticos de idade Juro-Cretácea, pertencentes à Formação Serra Geral, Grupo São Bento (Riccomini et al. 1984, Petri 1983, Milani et al. 1994). Tais derrames foram originários através de vulcanismo de fissura continental, apresentam espessura e extensão consideráveis e ocorrem de maneira contínua e abrangente em toda região sudoeste e oeste do Paraná. Normalmente apresentam espessuras que podem variar de 5 até mais de 50 metros, na forma de derrames tabuliformes, individualizados. Toda esta ocorrência está sobreposta aos sedimentos paleozóicos da unidade litoestratigráfica conhecida como Bacia do Paraná sendo recoberta por sedimentos recentes (Leinz, 1949, Schobbenhaus et al. 1984).

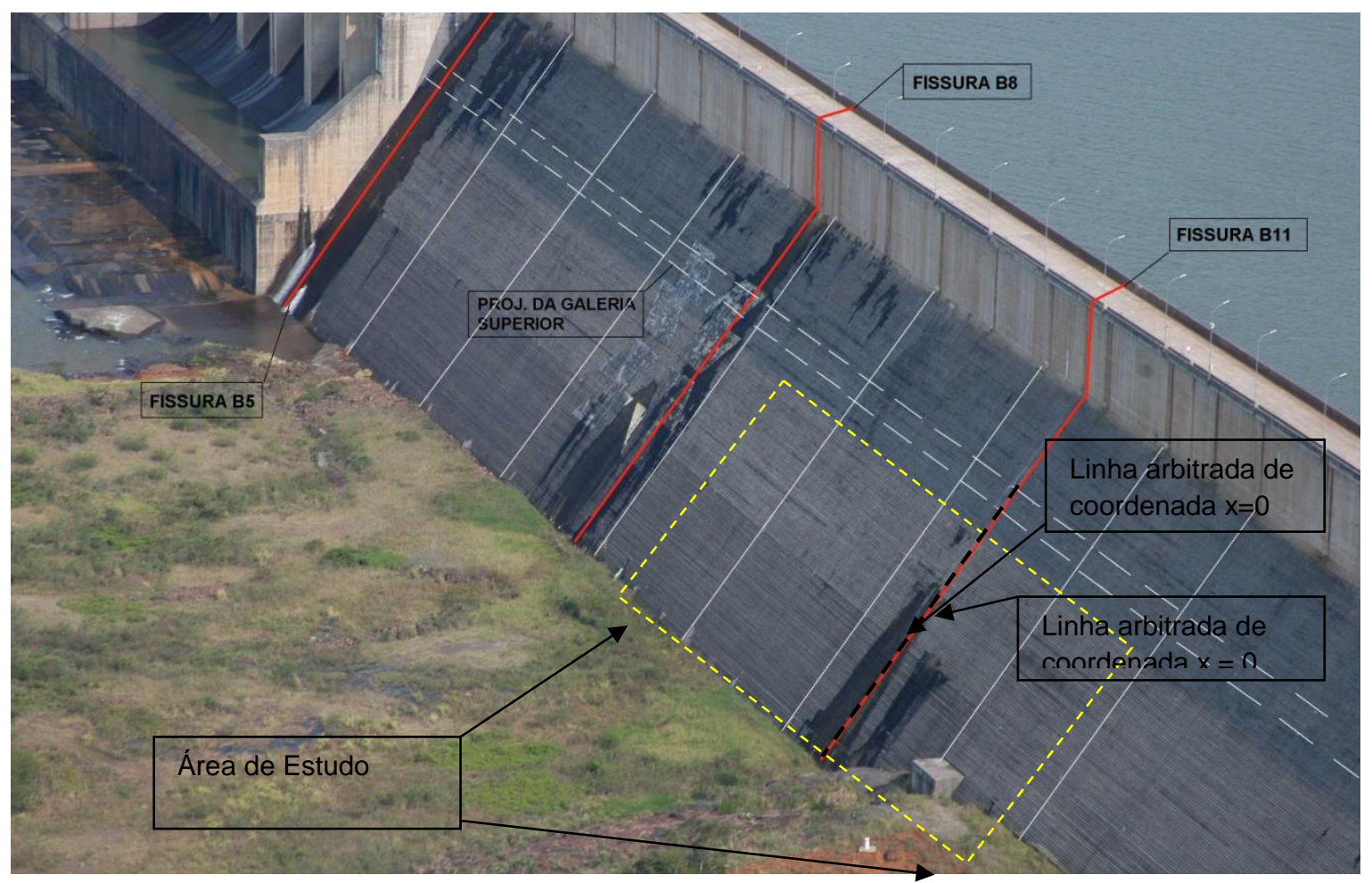

Figura 1: Foto área da barragem da UHE Gov. José Richa. As linhas vermelhas marcam as principais fissuras. (Soares, 2005). O retângulo amarelo demarca a área da barragem $\left(2000 \mathrm{~m}^{2}\right)$ onde foi realizado o estudo. 
As feições estruturais mais importantes da região em questão estão relacionadas às linhas de extensos fraturamentos dispostos segundo a direção preferencial NE e subordinadamente, NW (Zalán et al. 1987). Nos estudos de hidrelétricas do rio Iguaçu, a presença de falhamentos mais importantes, relacionadas a estas feições foram observadas, segundo as direções $\mathrm{N} 50^{\circ} / 70^{\circ} \mathrm{W}$ e $\mathrm{N} 50^{\circ} / 70^{\circ} \mathrm{E}$ (Levis et al 1998).

As características geológicas mencionadas influenciaram bastante o projeto e a construção da obra. A fundação da barragem de concreto-gravidade de Salto Caxias ficou inteiramente situada em rochas basálticas sãs e resistentes.

\section{Materiais e métodos}

A prospecção geofísica trata da detecção não invasiva e por conseqüência de interpretação indireta, em subsuperfície de corpos ou estruturas que apresentem algum tipo de contraste em uma ou mais propriedades físicas com o meio que o circunda. Existe uma variedade de métodos geofísicos que podem ser utilizados nos estudos geotécnicos (geoelétricos, sísmicos e gravimétricos). Para este caso optou-se a utilização dos métodos elétricos, por fornecerem melhores condições de contraste. Em nível de detalhe, os métodos geoelétricos que medem a eletrorresistividade podem caracterizar zonas condutoras que podem refletir fraturamento, alteração e mesmo vazios preenchidos por água e/ou lama.

Escolheu-se para esta pesquisa o método da eletrorresistividade (técnica do caminhamento com arranjo gradiente) e do potencial espontâneo devido à sua facilidade e rapidez na execução além de se tratar de métodos de baixo custo operacional o que possibilitaria à concessionária de energia do Estado (COPEL) sua utilização no monitoramento das demais usinas hidrelétricas.

\subsection{Arranjo gradiente}

A técnica do caminhamento elétrico, pertence ao método da eletrorresistividade e está baseado na interpretação do parâmetro físico investigado (neste caso a resistividade), obtido através de medidas realizadas na superfície investigada ao longo de um ou mais perfis horizontais e a profundidades determinadas.

$O$ arranjo gradiente consiste de uma linha de transmissão de corrente $A B$ fixa, com medidas efetuadas entre os eletrodos $M N$, que são deslocados sobre perfis paralelos à linha $A B$.

A profundidade de investigação cresce com o aumento da distância entre os eletrodos de corrente $(A B)$ e é sempre possível realizar vários gradientes simultaneamente, superpostos, com diferentes extensões de linha $A B$, (conforme foi executado a partir da segunda etapa de campo).

$O$ espaçamento entre os eletrodos $A B$ e $M N$ deve ser determinado em função dos objetivos do trabalho. Usualmente utiliza-se uma relação $A B / M N$ entre 30 e 40 para assegurar uma razão sinal/ruído satisfatória, preservando ainda razoável resolução lateral. A profundidade de investigação varia de $A B / 4$ em meio resistente, portanto pouco dissipativo, até $A B / 10$ em meio altamente condutor. Os resultados são apresentados em mapas de contorno ou em perfis justapostos. As anomalias podem ser interpretadas quanto à posição com boa resolução lateral.

Este ensaio foi realizado com resistivímetro marca Tectrol, modelo TDC1000/24R2A, além baterias externas (para fonte de energia), multímetro digital de marca $\mathrm{HC}$ Products Co. Ltd., modelo Protek 506 e cabos múltiplos. Nos eletrodos de referência e potencial foram usados potes cerâmicos com solução de sulfato de cobre (não polarizáveis), enquanto que os eletrodos de corrente foram "confeccionados" com papel alumínio imerso em poças de lodo com água salgada. As linhas de corrente tiveram espaçamentos $A B$ de 30, 40, 50, 60 e 80 metros, constituindo 5 (cinco) níveis de investigação. Os eletrodos de potencial no arranjo gradiente tiveram entre si espaçamento de 2 metros. A disposição de vários $A B^{\prime}$ 's no arranjo gradiente garantiu um aumento na profundidade investigada, enquanto que o pequeno espaçamento entre os eletrodos de potencial propiciou um maior detalhe da variação lateral do potencial e da resistividade.

\subsection{Método do potencial espontâneo}

O potencial espontâneo, tradução do termo inglês "Self Potential", (sigla SP) se baseia no fato de que mesmo na ausência de qualquer campo elétrico criado artificialmente, é possível medir uma diferença de potencial entre dois eletrodos dispostos no terreno, que pode variar de alguns milivolts até algumas dezenas de milivolts. A principal vantagem na utilização do método SP é seu baixo custo, bem como sua simplicidade de operação em campo.

São dois os tipos de potenciais de fluxo responsáveis pela movimentação dos eletrólitos e geração do campo elétrico: "per ascensum" e "per descensun". (Schlumberger, 1929 apud Orellana, 1972)

O fluxo "per descensun" ocorre quando a água que percola ao longo das falhas/fraturas das rochas ou através da rede de capilaridade (porosidade+conectividade) dos terrenos ou materiais permeáveis, tende a arrastar cátions, o que gera uma diferença de potencial responsável por anomalias positivas em locais saturados e anomalias negativas em locais de pouca saturação. Anomalias de SP causadas por fluxo "per descensun" são amplamente usadas para a determinação de vazamentos de água em barragens ou contaminações do lençol freático.

A medida SP necessita de eletrodos impolarizáveis, voltímetro com alta impedância de entrada $(\geq 10$ megaohms) e fios condutores isolados que conectam os eletrodos aos terminais do voltímetro. Para este ensaio foram utilizados eletrodos não polarizáveis (potes cerâmicos) com sulfato de cobre e multímetro digital de marca HC Products Co. Ltd., modelo Protek 506.

O ensaio de SP pode ser realizado através técnica dos gradientes (não confundir com arranjo gradiente da 
resistividade) ou por meio de base fixa (técnica dos potenciais).

No mapeamento de SP em Salto Caxias adotou-se a técnica de base fixa, em que todos os pontos da malha são medidos em relação a um ponto fixo. Esta técnica foi adotada por se apresentar menos suscetível à propagação de erro. O intervalo entre pontos ou estações de medida foi definido, após testes iniciais, em 2 (dois) metros.

\section{Aquisição geofísica}

O estudo foi realizado no período entre dezembro/06 e setembro/07 em quatro campanhas de campo. O constante monitoramento realizado após o enchimento do reservatório, verificou-se que a temperatura ambiente tem grande influência no maciço de CCR da barragem, principalmente nas medições de abertura e vazões de infiltração nas juntas e também nas fissuras.

Durante o período de inverno, de junho a setembro, quando as temperaturas registram valores freqüentes abaixo de $10 \circ \mathrm{C}$, há uma influência direta na 'trabalhabilidade' do maciço de CCR, retraindo-o e consequentemente abrindo as juntas e fissuras existentes na face de montante, ocasionando numa maior passagem da água, aumentando a vazão local. Desta maneira as campanhas de campo foram agendadas de modo a permitir a verificação deste fato.

A primeira impressão ao se observar a face de jusante da barragem da UHE Salto Caxias, é de que seria muito difícil conseguir um contato elétrico satisfatório entre os eletrodos e o concreto do corpo da barragem, pois fora das zonas de fraturas, visualmente, o concreto apresentava-se com uma aparência muito seca. Porém, por se tratar de um concreto de baixo consumo (conteúdo) de cimento por metro cúbico, o concreto compactado com rolo (CCR), utilizado na barragem, apresenta um coeficiente de permeabilidade maior que o coeficiente dos concretos tidos como convencionais, o que possibilita uma relativa "facilidade" na percolação de água/fluídos pelos seus poros.

Desta maneira, devido à maior permeabilidade do concreto CCR e a constante saturação do maciço de concreto, a dificuldade esperada para o método devido ao contato concreto-eletrodos, revelou-se menos crítica do que se imaginava.

Os degraus de jusante, de maneira geral, serviram como linhas de ensaio para os métodos geoelétricos. A linha tracejada que acompanha a faixa escura na Figura 1 , foi assumida como linha de coordenada $X=$ zero. $A$ partir de pontos amarrados e geo-referenciados utilizou-se trena para determinar as estações/pontos de medidas.

Com base nos resultados obtidos na primeira campanha de campo foram feitas 9 (nove) linhas de ensaio nos degraus, denominadas de $L+8, L+6, L+4, L+2, L 0, L-2, L-4, L-6$ e $L-8$, posicionadas em relação à trena da linha central da fissura ( $X=0$ ") em $+3,35 m, 0,00 m,-3,17 m,-6,55 m$, $10,00 m,-13,40 m,-16,75 m,-20,10 m$ e $-23,10$ metros respectivamente (Figura 2). Estas distâncias foram determinadas, em função da inclinação da face da barragem para possibilitar uma malha quadrada de $2 \times 2$ metros.

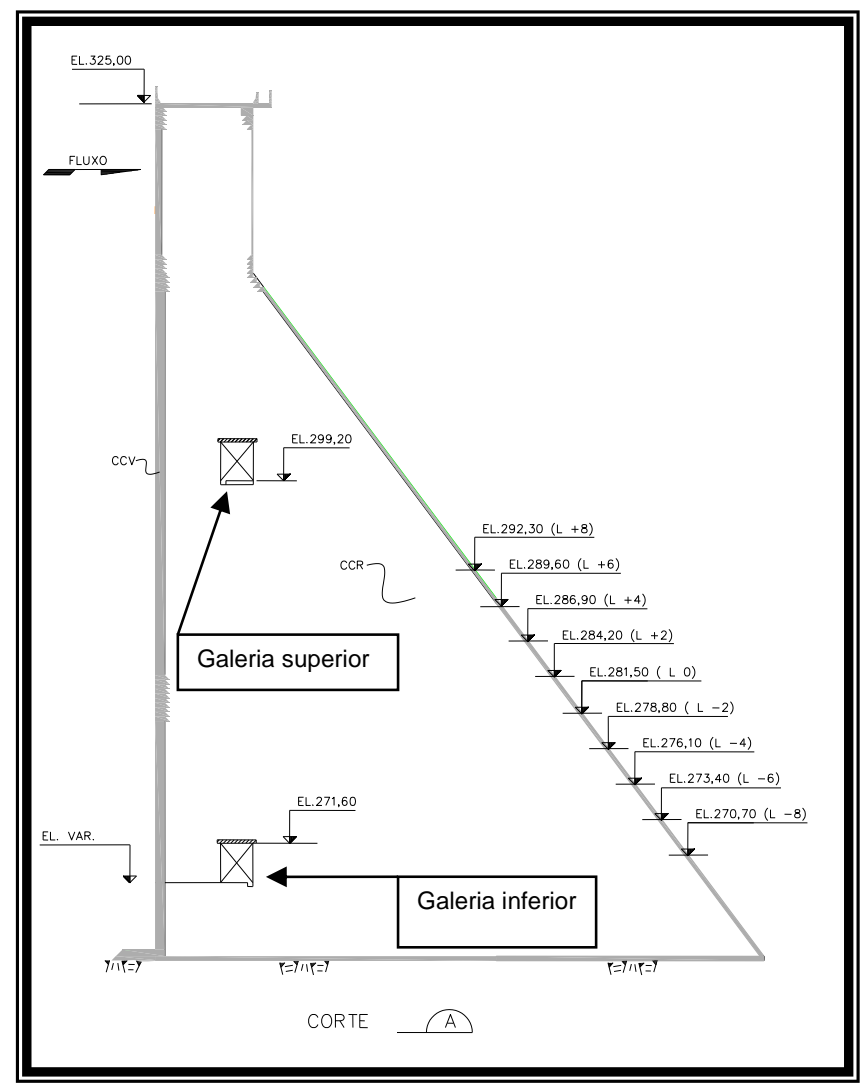

Figura 2: Corte transversal esquemático da barragem UHEGJR com o posicionamento das linhas de ensaio.

\section{Processamento dos dados e comentários}

Novamente ressalta-se que os métodos geofísicos têm certo grau de ambigüidade em sua interpretação. A modelagem numérica dos dados não tem solução única e as diversas técnicas de interpolação podem gerar efeitos enganosos nos limites das malhas.

As pseudo-seções do caminhamento elétrico com o arranjo gradiente e os levantamentos de SP foram tratados com os softwares Earthlmager 2D ${ }^{\circledR}$, versão 2.1.7 (AGIUSA) e Geosoft $^{\circledR}$ (Geosoft Incorporated, 1994), disponíveis no mercado.

Por se tratar de uma fase experimental, onde a disposição das linhas de ensaio não se mostrou eficaz, os resultados obtidos nos ensaios da primeira etapa de campo não foram considerados satisfatórios.

\subsection{Ensaios de resistividade com arranjo gradiente}

Neste trabalho a análise dos resultados é feita apenas sobre os dados de resistividade aparente, de forma qualitativa. Vale lembrar que a resistividade tem um objetivo amplo no estudo, buscando diagnosticar a aplicabilidade de métodos elétricos e eletromagnéticos em 
geral, além do objetivo específico de apoiar o levantamento de SP na determinação dos caminhos preferenciais de fluxo. A repetição do levantamento de resistividade em diferentes estações do ano, com vários meses de intervalo, foi para avaliar possíveis mudanças na resposta, que possam ser associadas seja à variação no grau de saturação ou na extensão da zona de fissuramento.

De alguma forma já foi possível verificar a consistência do levantamento de resistividade com o arranjo gradiente no corpo de concreto da barragem e também identificar uma resposta característica da faixa de fissuramento do Bloco 11.

Inicialmente os mapas de resistividade aparente de cada um dos levantamentos foram plotados utilizando diferentes escalas de cores. Para efeito de comparação do que ocorre
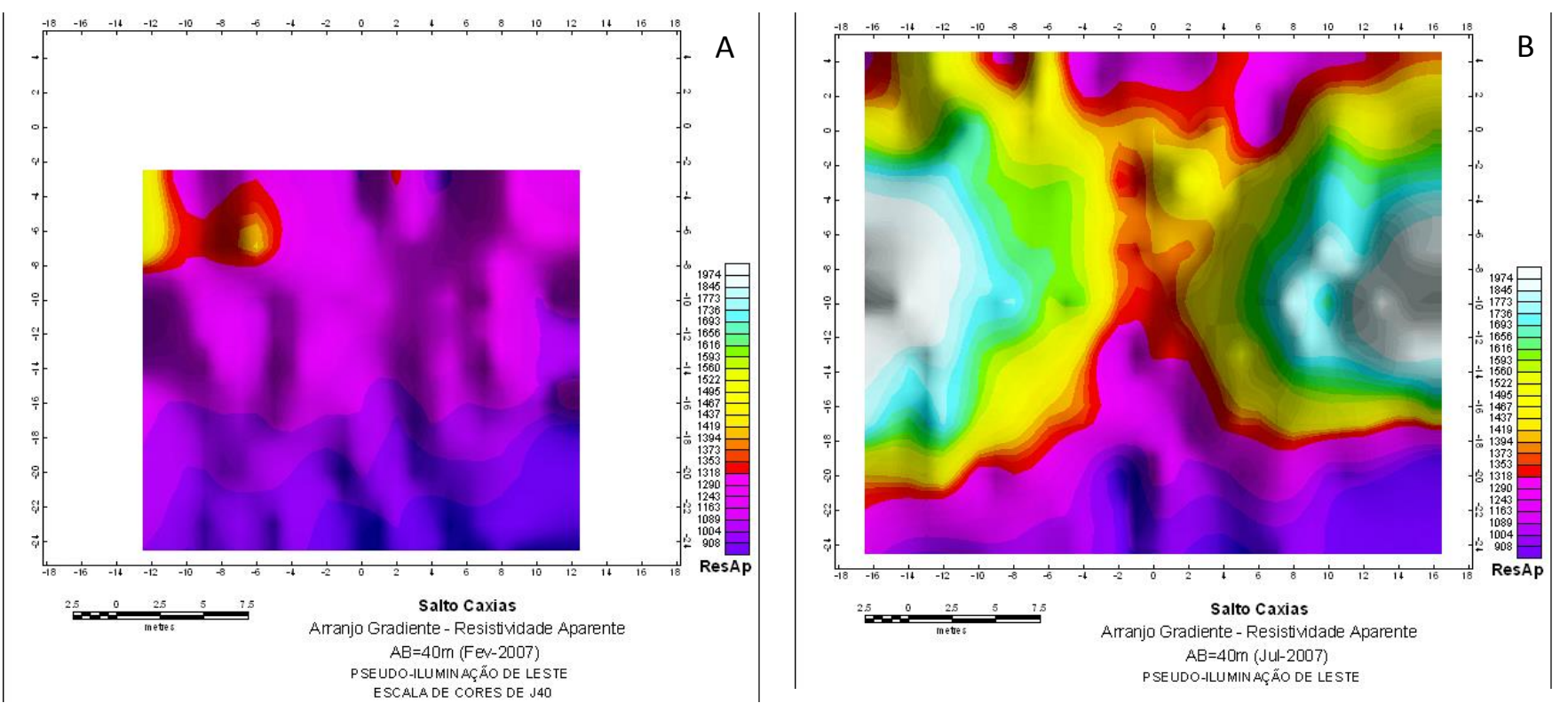

Figura 3: Mapas de resistividade aparente para o $A B=40 \mathrm{~m}$ : a) para o levantamento de fevereiro; b) para o levantamento de julho. Mesma escala de cores para ambos os mapas.
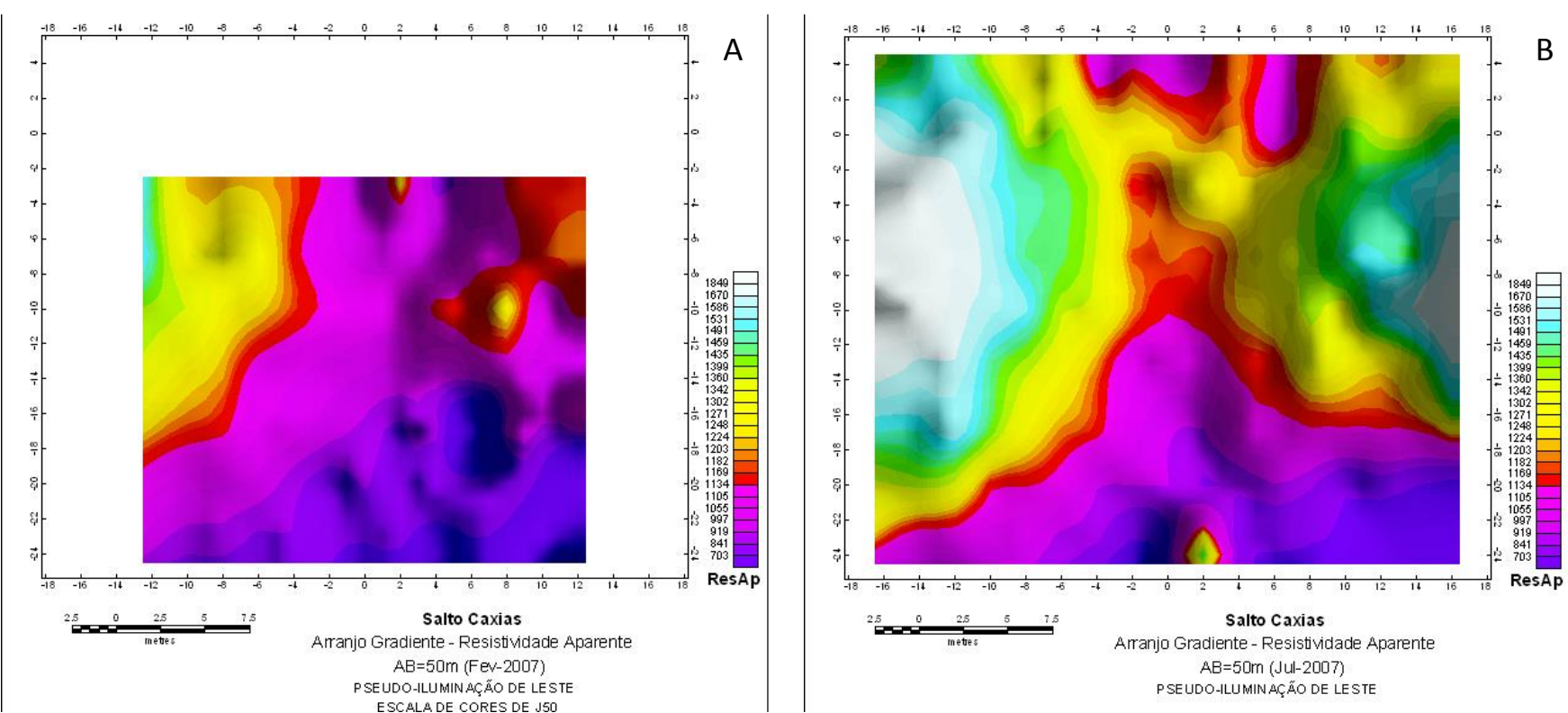

Figura 4: Mapas de resistividade aparente para o $A B=50 \mathrm{~m}$ : a) para o levantamento de fevereiro; b) para o levantamento de julho. Mesma escala de cores para ambos os mapas. 

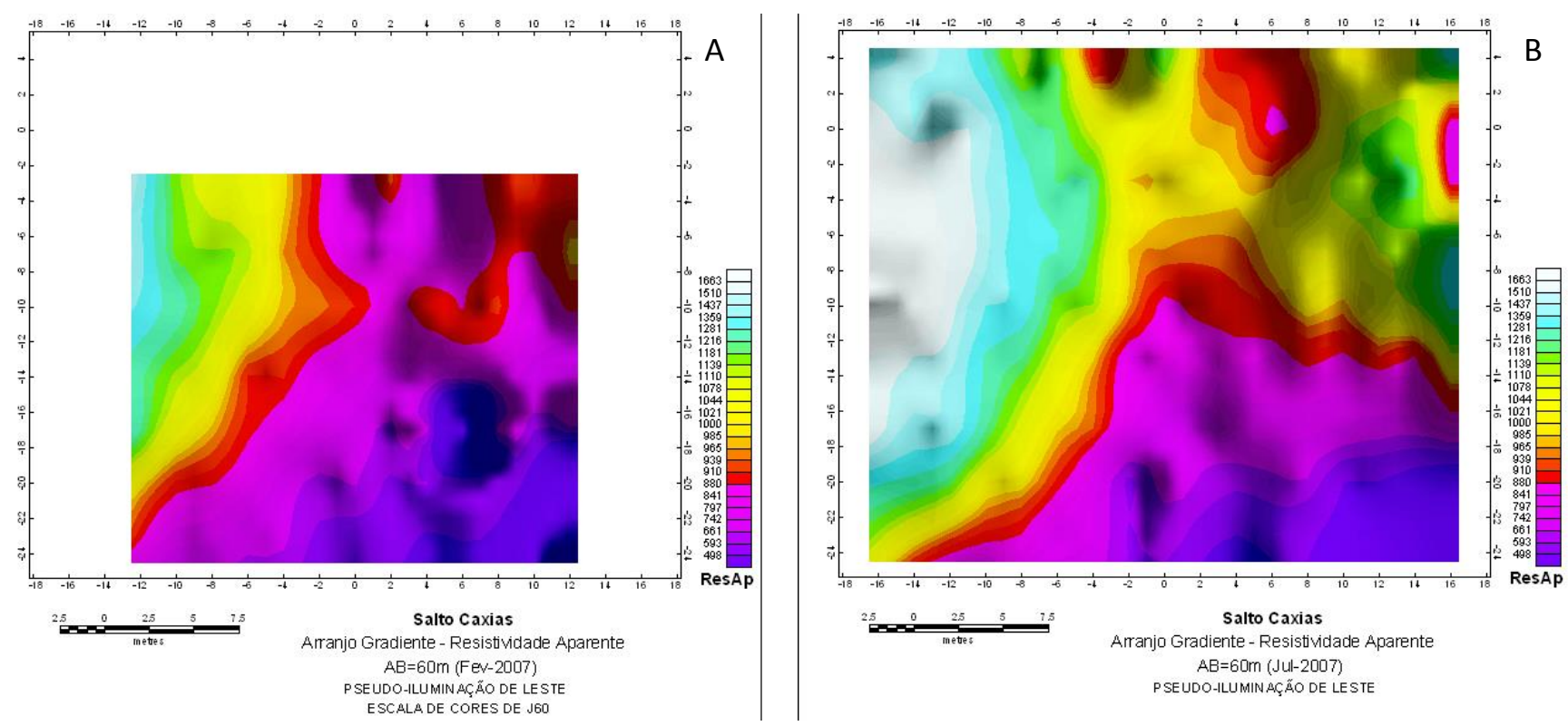

Figura 5: Mapas de resistividade aparente para o A6=60m: a) para o levantamento de fevereiro; b) para o levantamento de julho. Mesma escala de cores para ambos os mapas.
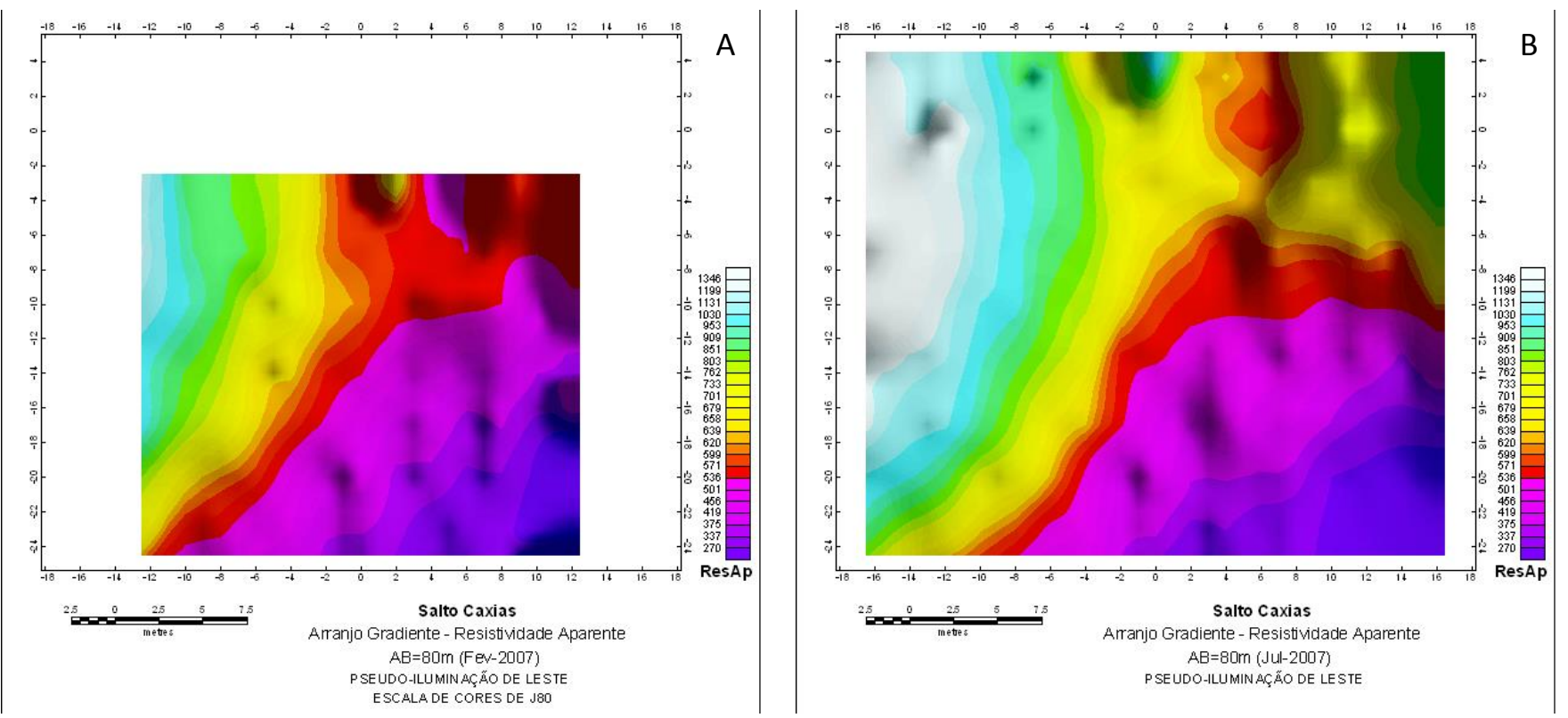

Figura 6: Mapas de resistividade aparente para o $A 6=80 \mathrm{~m}$ : a) para o levantamento de fevereiro; b) para o levantamento de julho. Mesma escala de cores para ambos os mapas.

Para finalizar a análise qualitativa dos dados de resistividade aparente, apresenta-se na Figura 7 os mapas da derivada direcional Dx na direção x (ao longo dos degraus) sobre os dados do levantamento de julho. É importante notar que ao longo do texto são utilizadas diferentes escalas de cores. $\mathrm{O}$ baixo de resistividade (alta condutividade) aparece no extremo vermelho quando são plotados mapas de resistividade. Já em outras plotagens como do SP e das derivadas da resistividade aparente, o vermelho é atribuído aos valores mais altos como usual. Observando-se então os mapas da derivada Dx na Figura 7, vê-se evidente o lineamento associado ao eixo condutor central discutido anteriormente. Espera-se que a derivada direcional Dx elimine em parte os efeitos de eletrodos que estejam presentes nos mapas de resistividade discutidos anteriormente, salientando lineamentos paralelos à faixa de fissuramento principal. Dois eixos são bem delineados. Eles aparecem com um lineamento de baixo nos valores da derivada à esquerda e um alto à direita. O eixo central é claramente associado à faixa de fissuramento principal, já o que aparece mais à esquerda deve ser melhor investigado. $O$ fato de até $O A B$ de $80 \mathrm{~m}$ mostrar o lineamento central não quer dizer que o mesmo seja resposta da rocha subjacente. Provavelmente a profundidade investigada por este $A B$ ainda é bastante influenciada pelo corpo de concreto. 

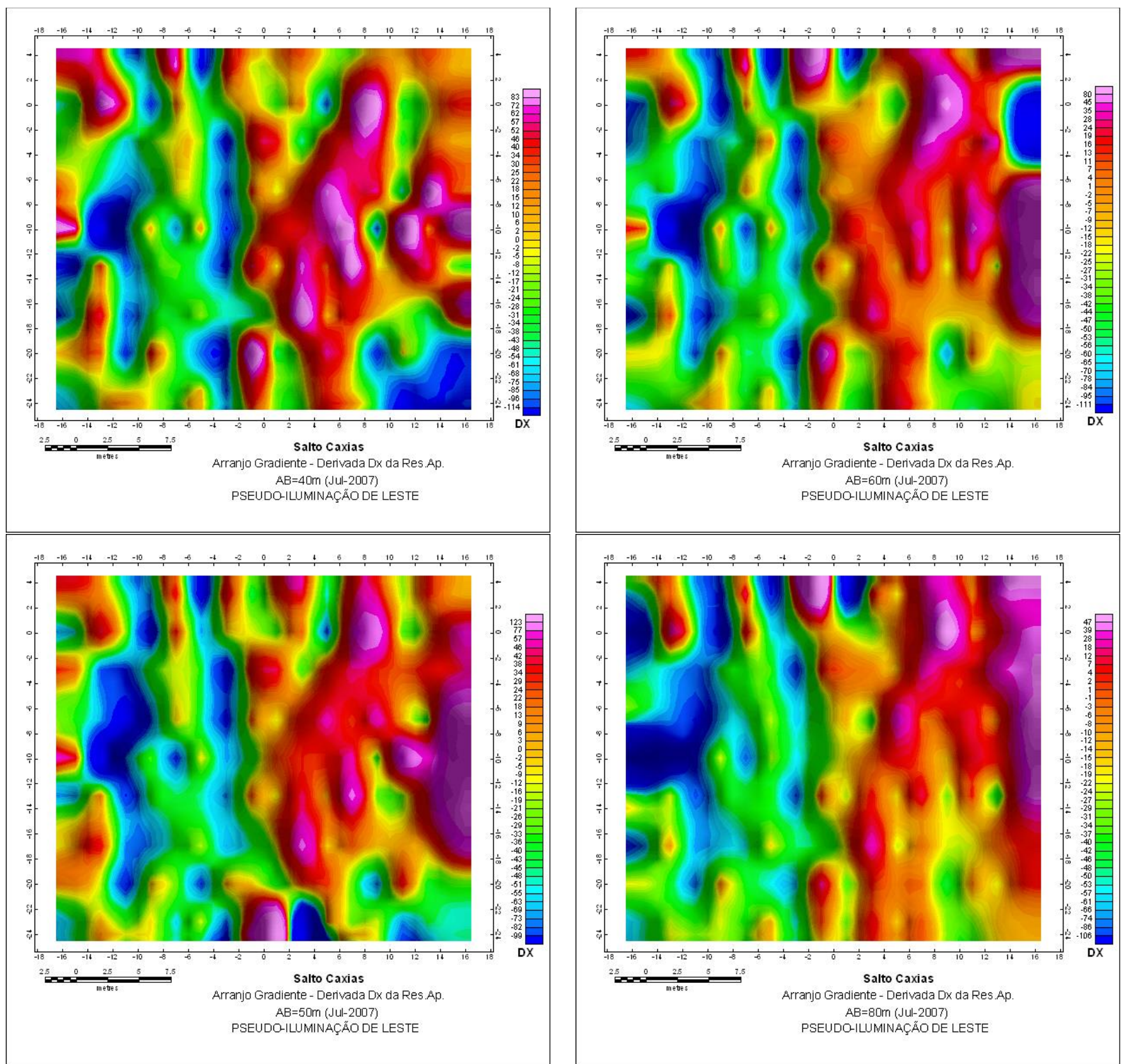

Figura 7: Derivada direcional $D x$ sobre os dados de resistividade aparente do levantamento gradiente de julho de 2007: $A B=40 \mathrm{~m}$ (esquerda superior); $A B=50 \mathrm{~m}$ (esquerda inferior); $A B=60 \mathrm{~m}$ (direita superior); $\mathrm{AB}=80 \mathrm{~m}$ (direita inferior).

\subsection{Potencial espontâneo}

Os dados de SP obtidos durante as campanhas de campo de fevereiro, julho e setembro de 2007 foram processados através do Geosoft ${ }^{\circledast}$ (Geosoft Incorporated, 1994), e estão apresentados como mapa de equipotenciais. Tais produtos podem ser interpretados qualitativamente quanto aos caminhos preferenciais da água. A determinação da profundidade em que estes caminhos se encontram pode ser facilitada pelo fato de as linhas (executadas nos degraus) estarem em cotas definidas.

Nas Figuras 8 e 9 estão apresentas as anomalias de SP observadas durante as campanhas de fevereiro e julho/07 com malha de 12 metros. Pode-se observar a influência da temperatura externa sobre a fissura, pois na campanha de julho (no inverno), temos dois eixos verticais bem evidentes, que correspondem à zona de fissura principal (no centro) e uma secundária (à direita) de menor amplitude, além de um eixo horizontal não observado durante a campanha de fevereiro/07 (verão). Esta situação pode ser observada "in loco", conforme mostra a Figura 10.

$\mathrm{Na}$ campanha de setembro/07 optou-se por ampliar a malha coberta pelo SP a fim de procurar sair da zona de influencia da fissura. Com o aumento da extensão das linhas de ensaio para 130 metros (65metros para cada lado a partir da linha central), pretendeu-se verificar as condições de fluxo de fluidos no interior da barragem. Adiante, na Figura 11, pode-se comparar os resultados obtidos durante as campanhas de campo de setembro e julho/07. 


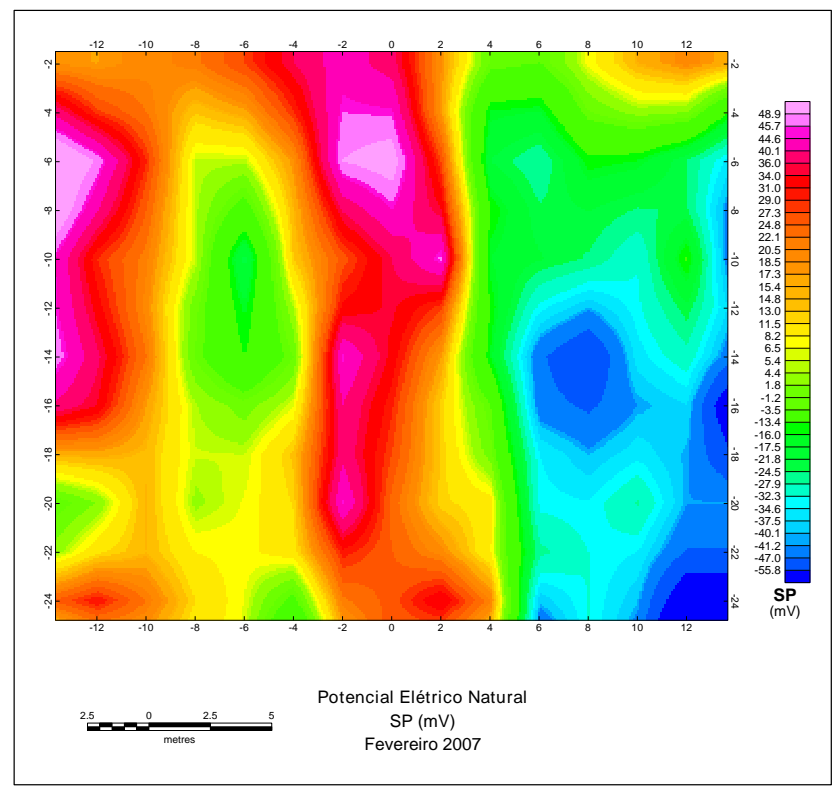

Figura 8: Mapa de potencial elétrico natural (SP). Campanha: Fevereiro.

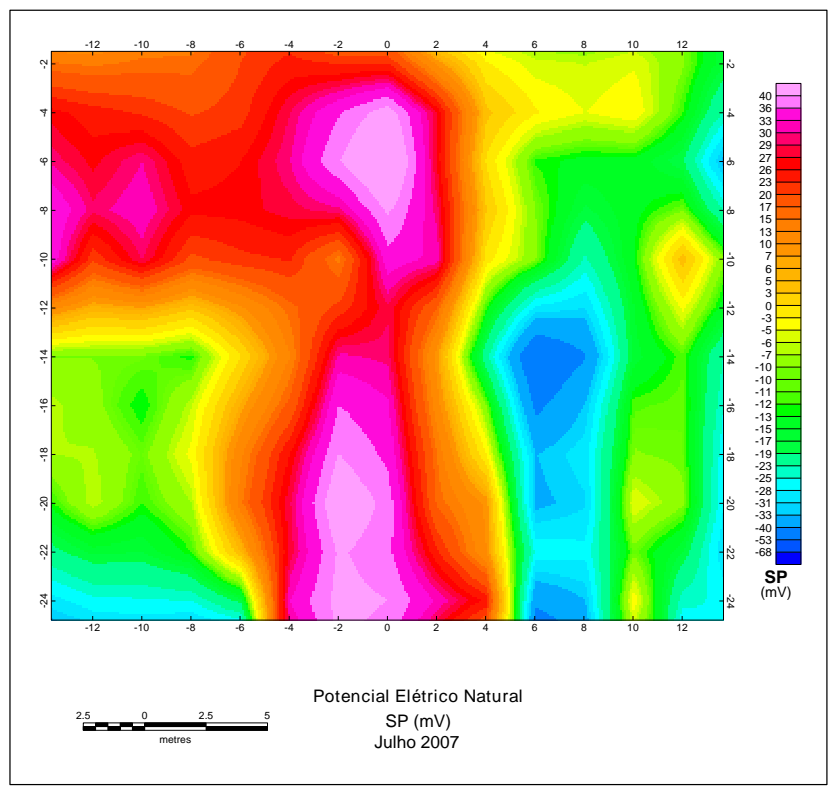

Figura 9: Mapa de potencial elétrico natural (SP). Campanha: Julho/07..
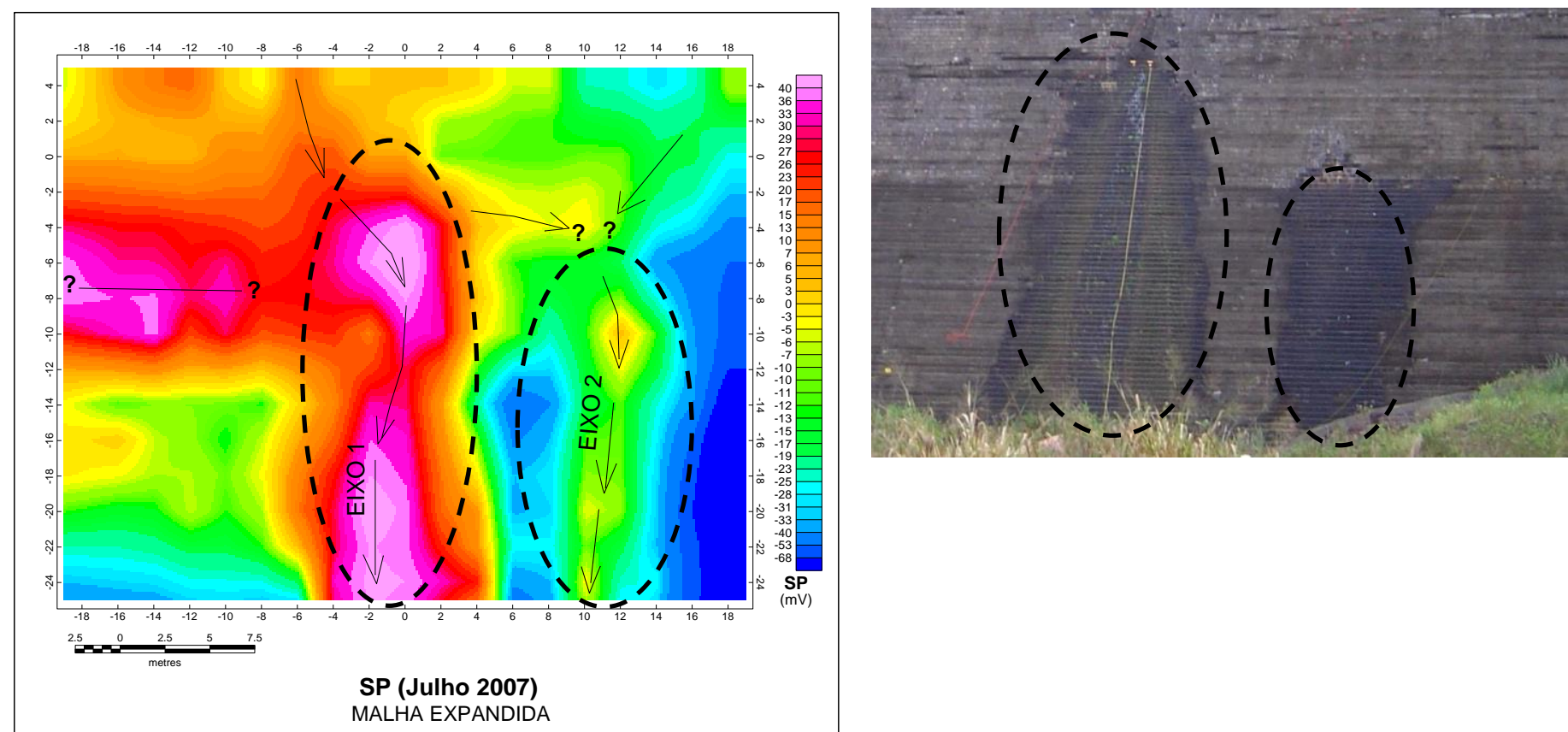

Figura 10: Mapa de potencial elétrico natural (SP). Campanha: Julho/07. Com malha expandida de 16 metros. Ao lado, a correlação com situação encontrada em campo.

Comparando-se o mapa de setembro com as imagens obtidas na campanha de julho (canto inferior esquerdo) pode-se observar que as duas anomalias principais de eixos 1 e 2 (na vertical) detectados nas etapas anteriores apresentam-se mais pronunciadas, reflexo talvez do aumento da circulação de fluidos pelo interior da barragem. Como não houve uma variação significativa no nível do reservatório, se comparado às etapas anteriores, pode-se correlacionar este "aumento" na umidade interna com uma possível retração da massa de concreto, o que acarretaria uma expansão na dimensão das fissuras. Em contra partida, a anomalia de eixo horizontal na linha L2, que estava presente no levantamento de julho, apresenta-se com menores proporções. Porém estas análises devem ser confirmadas através de outras informações como leituras nos outros equipamentos de monitoramento e as medições de vazão nos drenos.

O aumento da malha possibilitou um melhor mapeamento das condições de umidade interna da barragem. Outras variações de SP foram detectadas à esquerda da linha central, principalmente nas linhas L2 e L4 (com eixo horizontal), e outra a partir dos 65 metros a qual parece receber contribuição da carga hidráulica da fissura do bloco B8. 


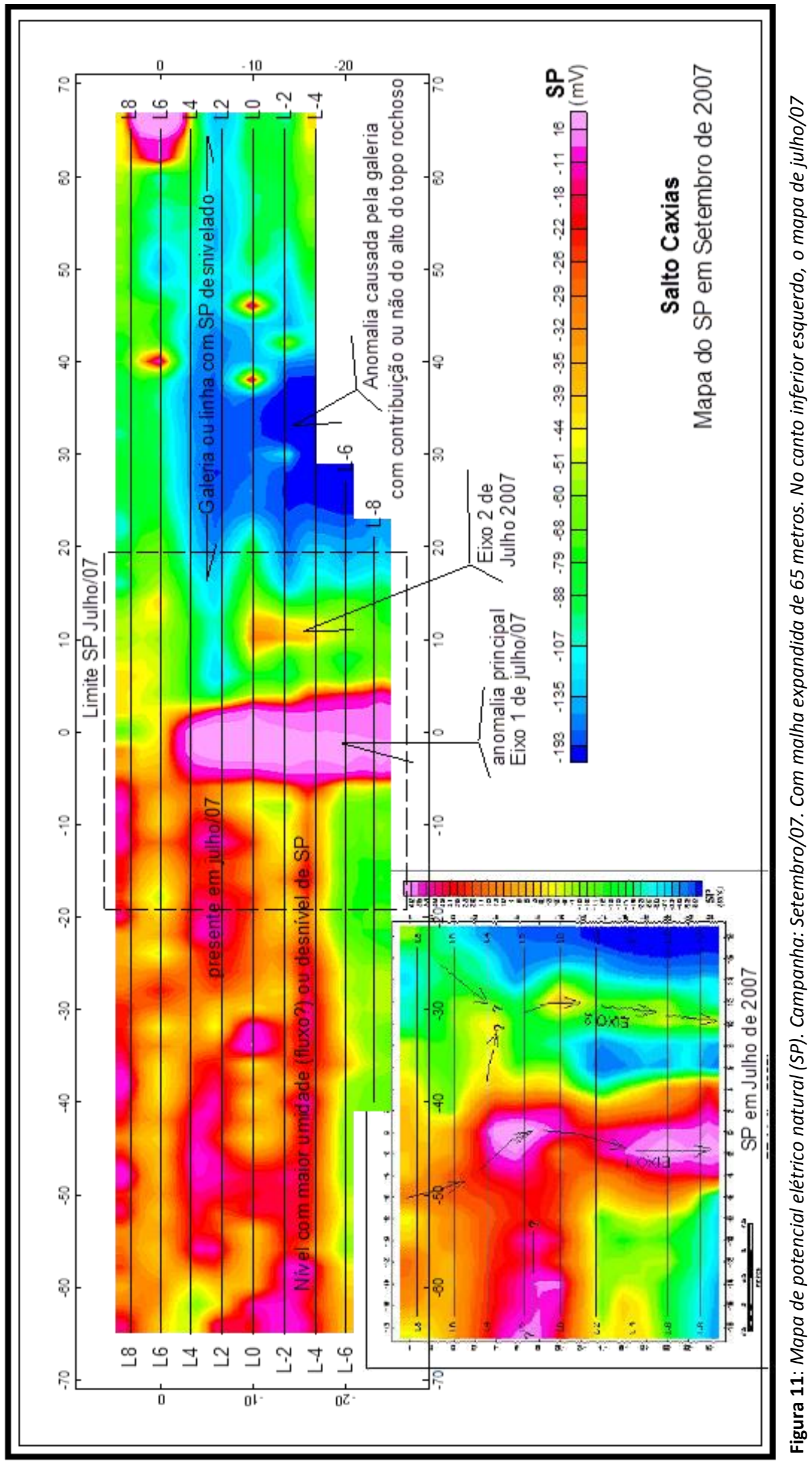


Na porção direta do mapa observa-se um baixo de SP com alguns "outliers" (pontos isolados de anomalia, provenientes de ruídos ou problemas de medida durante o ensaio).

Este comportamento anômalo tem forte contribuição da galeria inferior e também do topo rochoso intensamente fraturado, os quais mascaram as resposta de SP do concreto.

Para a comprovação desta hipótese deve-se recorrer à memória técnica do projeto a usina para uma pesquisa intensa na documentação e verificação das condições em que se encontrava o maciço rochoso do leito do rio, neste ponto, antes e durante a construção do empreendimento. Bem como se houve algum tipo de tratamento, e qual foi sua eficácia, nas fraturas de jusante.

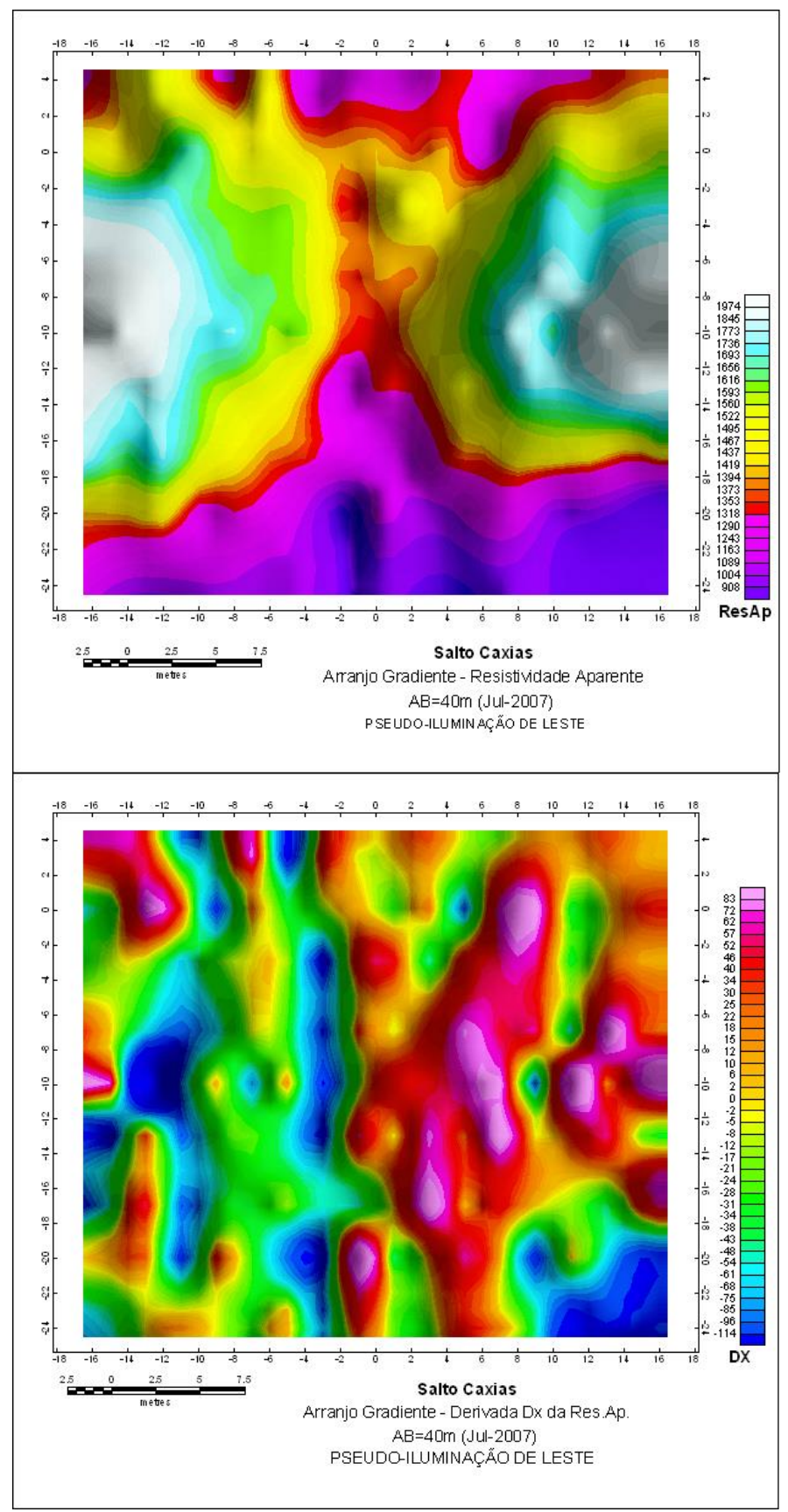

Numa análise comparativa, a Figura 12 deixa claro que, para este caso, a associação resistividade - SP é muito indicada para a investigação proposta.

\section{Conclusões e recomendações}

A proposta inicial desta pesquisa foi de desenvolver metodologias ou ferramentas, eficientes e a baixo custo, que pudessem auxiliar nas atividades de monitoramento das condições estruturais das barragens das usinas hidrelétricas no Estado.

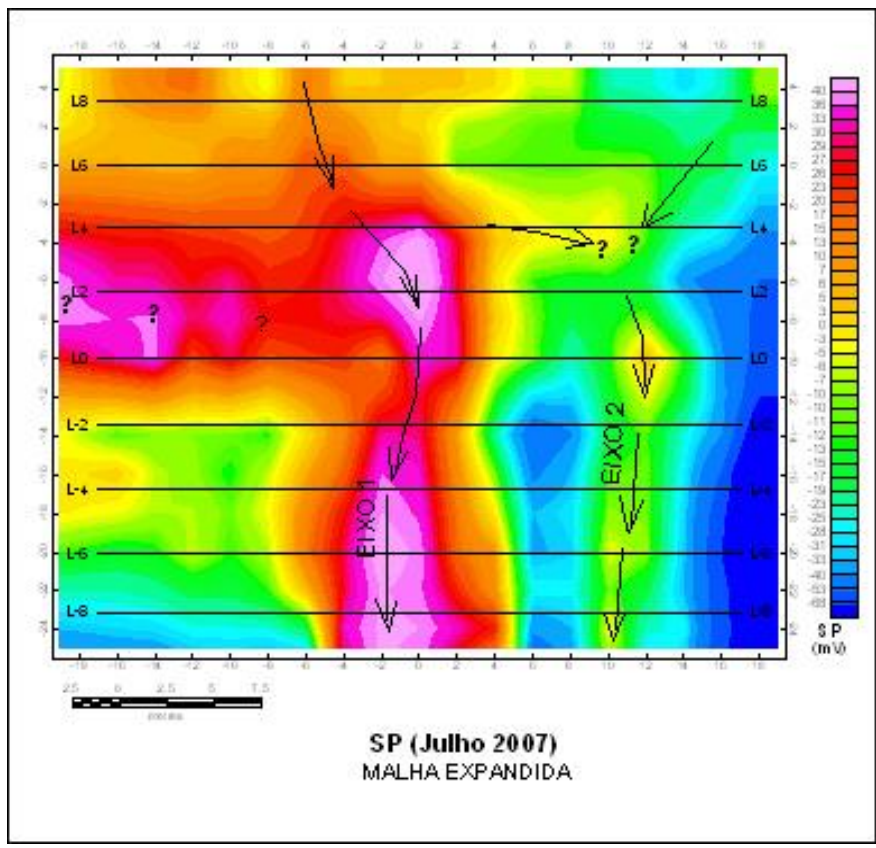

Figura 12: Correlação entre a resistividade aparente para $A B=40 \mathrm{~m}$ (canto superior esquerdo) com a sua derivada Dx (canto inferior esquerdo) e com o SP (canto superior direito) do levantamento de julho. 
Com caráter inovador, devido às condições construtivas da barragem, este trabalho pretendeu adequar os métodos e técnicas geofísicas à estas novas condições geotécnicas. A utilização de métodos geoelétricos em barragem de concreto exigiu uma adequação e até certas doses de criatividade quanto aos equipamentos e arranjos de campo.

Desta maneira ressalta-se que a escolha do método, técnica e/ou arranjo geofísico a ser empregado dependerá sobremaneira do maciço, das condições construtivas, dos objetivos almejados e do grau de detalhe requerido.

Independentemente do tipo de construção, é aconselhável a utilização de dois ou mais métodos/técnicas de investigação, comparados e correlacionados com outros sistemas de monitoramento existentes na estrutura, sempre que isto for possível.

A eletrorresistividade é um método amplo e aplicável quase que em todas as situações.

Para os ensaios realizados na barragem de Salto Caxias, a técnica do caminhamento com o arranjo gradiente buscou diagnosticar a aplicabilidade de métodos elétricos e eletromagnéticos em geral, além do objetivo específico de apoiar o levantamento de SP na determinação dos caminhos preferenciais de fluxo. Nesta pesquisa a análise dos resultados é feita apenas sobre os dados de resistividade aparente, de forma qualitativa mas mostrouse extremamente eficiente.

O método Potencial Elétrico Natural mostrou-se uma excelente ferramenta de investigação (detecção e mapeamento) dos caminhos preferenciais de fluxo no talude jusante da barragem de Salto Caxias. Além das respostas marcantes ao longo de fraturas com fluxo visível, o método apresenta bom rendimento e baixo custo tanto de execução como de investimento necessário em instrumentação.

Estudos posteriores realizados em áreas distintas poderão comprovar melhor a eficácia de métodos para investigação nestas condições. Porém como a geofísica é uma ciência interpretativa, onde o resultado único não ocorre, cabe aos profissionais envolvidos, geofísicos, geólogos e engenheiros, interagirem na análise do problema e na busca de soluções.

Agradecimentos: À Cia. Paranaense Energia - COPEL, às instituições envolvidas no projeto, Instituto de Tecnologia para o Desenvolvimento - LACTEC, Universidade Federal do Paraná - UFPR, Geodecon - Geologia e Geofísica e ao Conselho Nacional de Desenvolvimento Cientifico e Tecnológico - CNPq pelo benefício da lei no. 8010/90.

\section{Referências bibliográficas}

CORWIN R.W. 1989. Geotechnical Applications of the SelfPotential Method, US Army Corps of Engineers, Washington, DC.

ELLERT N., SANCHES W. 1982. Detecção de fuga d'água em reservatórios utilizando técnicas geofísicas (potencial espontâneo). In: Boletim IG-USP, 13, 15-24.

GALLAS J.D.F. 2000. Principais métodos geoelétricos e suas aplicações em prospecção mineral, hidrogeologia, geologia de engenharia e geologia ambiental. Tese de doutorado. Instituto de Geociências e Ciências Exatas. Campus Rio Claro. UNESP. Rio Claro. 174p.

IYOMASA W. S., BLANCO R.G., STRUFALDI E.G.B., OLIVITO J.P.R., ROCHA R., VASCONCELOS S.E., MELO I.A., SILVA A.R. 2005. Levantamento geológico e geofísico aplicado à investigação de fluxo de água de sub-superfície: um exemplo na barragem do Rio Atibainha, SP. In: 11‥CONGRESSO BRASILEIRO DE GEOLOGIA DE ENGENHARIA E AMBIENTAL, Florianópolis. Anais ABGE, 1753-1767.

LEINZ V. 1949. Contribuição à geologia dos derrames basálticos do Sul do Brasil. FFCL/USP. Boletim Geologia, 5, 61.

LEVIS P., MARQUES FILHO P.L., TERRES, J. F., 1998. Aspectos Geológicos das Barragens da derivação do Rio Jordão e de Salto Caxias. In: III Seminário Nacional de Concreto Compactado com Rolo. Foz do Iguaçu, PR.

MILANI E.J., FRANÇA A.B., SCHNEIDER R.L. 1994. Bacia do Paraná. Bol. Geoc. Petrobrás 8(1), 69-82.

OLIVEIRA A.M.S., BRITO S.N.A. 1998. Geologia de Engenharia, São Paulo, ABGE 587p.

ORELLANA E. 1972. Prospeccion geoelectrica em corriente continua. Madrid, Ed. Paraninfo, Biblioteca Técnica Philips, $523 p$.

PETRI S., FÚLFARO J.V. 1983. Geologia do Brasil. São Paulo, 558p.
RICCOMINI C., GIMENEZ FILHO A., ALMEIDA F.F.M. 1984. Considerações sobre a estratigrafia do Permo-Triássico na região da Serra do Cadeado, Paraná. In: CONGRESSO BRASILEIRO DE GEOLOGIA, 33, Rio de Janeiro. Anais SBG, 2, 754-763.

SCHOBBENHAUS C., ALMEIDA CAMPOS D., DERZE G.R., ASMUS H.E. 1984 Geologia do Brasil. Brasília, DNPM, 501p.

SOARES M.A. 2005. Relatório técnico - Junta de Consultores, SCXRT-001/2005-RO. COPEL GERAÇÃO/SPG/ENGC. Curitiba, PR,. $103 p$

ZALÁN P.V., WOLF S., ASTOLFI M.A.M., VIERA .S., CONCIEÇÃO J.C.J., NETO E.V.S., MARQUES A. 1987. Tectônica e sedimentação da Bacia do Paraná. III Simpósio Sul-Brasileiro de Geologia, 1, 441-473.
Manuscrito ID10481

Submetido em fevereiro de 2008 Aceito em junho de 2009 